\title{
A quality-of-life measure for adults with primary ciliary dyskinesia: QOL-PCD
}

\author{
Jane S. Lucas 1,2,3,7, Laura Behan 1,2,3,4,7, Audrey Dunn Galvin ${ }^{4}$, Adrianne Alpern ${ }^{5}$, \\ Anjana M. Morris ${ }^{5}$, Mary P. Carroll ${ }^{1,2,3}$, Michael R. Knowles ${ }^{6}$, Margaret W. Leigh $^{6}$ \\ and Alexandra L. Quittner ${ }^{5}$ \\ Affiliations: ${ }^{1}$ Primary Ciliary Dyskinesia Centre, University Hospital Southampton NHS Foundation Trust, \\ Southampton, UK. ${ }^{2}$ NIHR Southampton Respiratory Biomedical Research Unit, University of Southampton and \\ University Hospital Southampton NHS Foundation Trust, Southampton, UK. ${ }^{3}$ Academic Unit of Clinical and \\ Experimental Sciences Faculty of Medicine, University of Southampton, Southampton, UK. ${ }^{4}$ Dept of Applied \\ Psychology, University College Cork, Cork, Ireland. ${ }^{5}$ Dept of Psychology, University of Miami, Coral Gables, FL, \\ USA. ${ }^{6}$ Dept of Medicine and Pediatrics, University of North Carolina School of Medicine, Chapel Hill, NC, USA. \\ ${ }^{7}$ Both authors contributed equally.
}

Correspondence: Jane Lucas, Clinical and Experimental Sciences Academic Unit (Mail Point 803), University of Southampton Faculty of Medicine, University Hospital Southampton NHS Foundation Trust, Tremona Road, Southampton, S016 6YD, UK. E-mail: jlucas1dasoton.ac.uk

ABSTRACT Primary ciliary dyskinesia (PCD) is characterised by chronic suppurative lung disease, rhino-sinusitis, hearing impairment and sub-fertility. We have developed the first multidimensional measure to assess health-related quality of life (HRQoL) in adults with PCD (QOL-PCD).

Following a literature review and expert panel meeting, open-ended interviews with patients investigated the impact of PCD on HRQoL in the UK and North America $(n=21)$. Transcripts were content analysed to derive saturation matrices. Items were rated for relevance by patients $(n=49)$. Saturation matrices, relevance scores, literature review, evaluation of existing measures, and expert opinion contributed to development of a preliminary questionnaire. The questionnaire was refined following cognitive interviews $(n=18)$.

Open-ended interviews identified a spectrum of issues unique to adults with PCD. Saturation matrices confirmed comprehensive coverage of content. QOL-PCD includes 48 items covering the following seven domains: Physical Functioning, Emotional Functioning, Treatment Burden, Respiratory and Sinus Symptoms, Ears and Hearing, Social Functioning, and Vitality and Health Perceptions. Cognitive testing confirmed that content was comprehensive and the items were well-understood by respondents.

Content validity and cognitive testing supported the items and structure. QOL-PCD has been translated into other languages and is awaiting psychometric testing.

@ERSpublications

QOL-PCD: quality of life measure for primary ciliary dyskinesia is ready for multi-national psychometric testing http://ow.ly/KAYyG

This article has supplementary material available from erj.ersjournals.com

Received: Nov 222014 | Accepted after revision: March 072015 | First published online: May 142015

Support statement: The research leading to these results has received funding from the European Union's Seventh Framework Programme under EC-GA No. 305404 BESTCILIA. In addition MRK and MWL receive grant support (U54HL096458) from the National Institutes of Health (NIH) through collaboration between the NIH Office of Rare Diseases Research (ORDR) at the National Center for Advancing Translational Science (NCATS), and the National Heart, Lung \& Blood Institute (NHLBI).; AQ was supported from an Investigator-initiated grant, Gilead Sciences; the National PCD Service in Southampton UK is commissioned and funded by NHS England.

Conflict of interest: Disclosures can be found alongside the online version of this article at erj.ersjournals.com

Copyright $\odot$ ERS 2015. ERJ Open articles are open access and distributed under the terms of the Creative Commons Attribution Non-Commercial Licence 4.0. 


\section{Introduction}

Primary ciliary dyskinesia (PCD) is a rare disease $(\sim 1$ in 15000 people) inherited in a genetically heterogeneous, autosomal recessive pattern [1-3]. It is characterised by chronic infection of the upper and lower airways caused by impaired mucociliary clearance as a consequence of abnormal function of motile cilia. In healthy individuals, cilia clear airway mucus, bacteria and debris by coordinated beating. The ciliary dysfunction in PCD leads to a daily wet cough, recurrent chest infections and rhino-sinusitis. By adulthood, bronchiectasis is invariable and many patients develop respiratory failure [4]. Motile cilia are important in organ systems besides the airways, such as the embryonic node, sperm flagella and the female reproductive tract. Therefore, patients frequently have problems caused by non-respiratory dysmotile cilia, e.g. serous otitis media ("glue ear") leading to hearing impairment and immotile sperm causing infertility). The cilia of the embryonic node, responsible for left-right asymmetry of organs, are similar in structure to respiratory cilia. Dysfunction of embryonic nodal cilia in PCD causes laterality defects, including situs inversus (chest and abdominal organs are mirror image of normal; seen in approximately $40 \%$ of cases) and situs ambiguous (disturbance of the usual left and right distribution of the thoracic and abdominal organs which does not entirely correspond to mirror image; seen in approximately $10 \%$ of cases) and can be associated with congenital heterotaxic heart disease in approximately $2-3 \%$ of cases [5].

Monitoring of disease progression and evaluation of therapeutic options has been hampered by a lack of disease-specific outcome measures. Spirometry is an insensitive marker of progressive lung disease, which is evident using high-resolution computed tomography (HRCT) [6]. Although HRCT is a useful staging test, it is an impractical monitoring tool. Lung clearance index (LCI), measured by multiple breath washout, has been investigated as a potential tool for monitoring at specialist centres using sulphur hexafluoride $\left(\mathrm{SF}_{6}\right)$ as a tracer gas $[7,8]$. However, contrary to findings in cystic fibrosis (CF), LCI does not appear to be a sensitive test of airway disease in advanced PCD [7]. Furthermore, physiological measures provide information on objective indicators of health to patients and clinicians, but these measures do not reflect the patient perceptions of the impact of the disease on symptoms as well as physical, social and emotional functioning.

Thus, measures are needed to assess the impact of PCD, from the patient's perspective, on all domains of patient functioning [9-11]. Health-related quality of life (HRQoL) measures have become a vital and necessary component of patient-reported outcomes (PROs) in populations with chronic disease [12]. The US Food and Drug Administration (FDA) defines HRQoL as the patient's perception of how they "survive, feel, and function" [13]. We used a model for HRQoL originally proposed by WILSON and CLEARY [14] and revised by FerRANs et al. [15]. There is extensive agreement that assessment of HRQoL should encompass, at minimum, physical, social and emotional well-being and symptoms which allow for a multidimensional, systematic measure of how the illness and its treatment impact symptoms and other domains of functioning.

Existing PROs do not assess the disease-specific effects of PCD on daily symptoms and functioning. Most studies have utilised either generic (e.g. Short Form 36 Health Survey) or broad-based respiratory questionnaires, such as the St George's Respiratory Questionnaire (SGRQ) [16-19] and two additional studies have utilised qualitative interview methods [20,21]. These PROs have a number of limitations for assessing HRQoL in adults with PCD. For example, the SGRQ was developed for patients with chronic obstructive airways disease and, thus, has a limited number of respiratory symptoms, no items relevant to ear, nose and throat disease or fertility problems, long and variable recall periods and considerable respondent burden (e.g. nearly an hour to complete). Thus, there was an urgent need to develop a disease-specific measure for adults with PCD. These tools can be used to document the progression of disease, monitor patients clinically and serve as an outcome measure for clinical trials of new therapies.

Our ultimate goal is to develop a PCD-specific HRQoL instrument for use as a primary or secondary outcome measure in large, randomised clinical trials. To recruit adequate numbers of participants, multi-centre and multi-national collaboration was required. Therefore, researchers from the UK, North America and Ireland worked closely to develop age-specific questionnaires (child, adolescent, parent-proxy and adult) using guidance developed by the FDA and European Agency for the Evaluation of Medicinal Products (EMEA) [13, 22, 23]. Development of the child, adolescent and parent-proxy versions will be reported in a separate manuscript. This manuscript describes the development process for the QOL-PCD Adult version which included the following phases: 1) literature review and expert panels; 2) open-ended interviews with patients in in UK, USA and Canada; 3) item generation; 4) cognitive testing; and 5) refinement of the draft measure. QOL-PCD is now being validated in Europe, USA and Canada; the psychometric reliability and validity will be reported when these studies are complete.

\section{Methods}

The protocol for development of the QOL-PCD complied with the FDA and EMEA requirements. The study was approved by Southampton and South West Hampshire Research Ethics Committee 
(Southampton, UK) A 07/Q1702/109 and by the University of Miami Institutional Review Board (Miami, FL, USA). Informed consent was obtained prior to interviews.

\section{Literature review and expert panel}

First, a systematic literature review was conducted to identify key symptoms and effects of PCD on patient functioning. MEDLINE and EMBASE were searched, and additional references were sought through citations in the identified studies. Abstracts were reviewed and manuscripts sourced for research investigating the effects of PCD on adults.

In the next step, expert clinicians, allied health professionals and researchers met to discuss their own perceptions of the impact of PCD on adults, based on their clinical experiences. These sources of information contributed to a long list of items patients rated for relevance. These items also informed the development of the open-ended interview guide.

\section{Participants}

In the UK, participants for the open-ended and cognitive interviews were recruited from PCD clinics and from an advert through the PCD Family Support Group UK. A list of potential items was sent to the Family Support Group in the UK to rate their relevance. Participants in North America were recruited from a cohort of PCD patients evaluated at the University of North Carolina, as well as from the US PCD Foundation's registry of patients. Expert opinion was also sought during the item generation and item reduction phases from members of the European PCD Group.

Criteria for participation in the open-ended and cognitive interviews included age $\geqslant 18$ years with a diagnosis of PCD. Patients were recruited from English-speaking countries: UK, USA and Canada. UK participants had an existing diagnosis from one of the English diagnostic centres $[1,24]$ based on clinical phenotype plus high-speed video analysis of ciliary function and/or assessment of ciliary ultrastructure by electron microscopy. North American participants were diagnosed at a specialised PCD research center, based on: a compatible clinical phenotype plus defect in ciliary ultrastructure and/or identification of biallellic disease-causing mutations in one of the PCD genes.

\section{Open-ended interviews}

In-depth interviews were conducted either in-person or by phone to elicit the effects of PCD from the patients' perspective. Interviews were conducted in the UK by L. Behan and in USA and Canada by A. L. Quittner, A. Alpern and A.M. Morris. All participants were fluent in English. We attempted to interview patients who were geographically representative and clinically stable. The audio of all interviews was recorded and transcribed for content analysis using either NVivo (version 8 2008; QSR International Pty Ltd, Daresbury, UK) in the UK or Atlas.ti (Version 7.0; Scientific Software Development, Corvallis, OR, USA) in the USA. Thematic coding was used to identify key symptoms and psychosocial impacts. Two members of each research team coded the interview transcripts using consensus coding. When there was a discrepancy, this was discussed and resolved within the pair of coders. We did not calculate percentage agreement since we used a consensus coding process. These data were then analysed to identify critical items based on frequency of endorsement. Content analysis of these transcripts yielded saturation and indicated that the measure was comprehensive and that all relevant items were included.

\section{Item generation}

Questions from the literature review, expert panel and open-ended interviews were also sent by post to respondents of an advert circulated to members of the PCD Support Group and to adult patients at PCD clinics in the UK. A pre-paid envelope and covering letter was included. Participants rated each item using a 5-point Likert scale (1: "not relevant"; to 5: "highly relevant").

Items for the initial QOL-PCD measure were based primarily on the patient-based content analysis. We discussed these results in a series of teleconferences chaired by J.S. Lucas. Each meeting included clinicians, psychologists and interviewers from Ireland, the UK and the USA. Decisions made using a modified Delphi approach guided by two main principles. The primary criterion for including an item was its impact on HRQoL, measured by the frequency with which items were mentioned across patients and in relation to other items mentioned. There was no pre-determined frequency required for inclusion of an item, but the researchers considered the frequency each item was mentioned relative to the other items in that domain. They also considered the importance interviewees placed on these items. Secondly, patients' ratings of relevance from the UK survey were considered. For each item, decisions were made to include an item based on our discussion. When there was initial disagreement, the chair invited each individual to explain their rationale. Unanimous agreement was achieved within two rounds of 
discussion. Finally, we determined that all of the content had been identified based on saturation matrices in the UK and US, which showed that no new content emerged after six patients, on average, in each country. We included at least four items on each subscale to ensure adequate internal consistency.

\section{Construct of prototype questionnaire}

Agreement on item selection and wording was achieved during multi-disciplinary, multinational conference calls. Selected items were written using patient language obtained in the qualitative interviews and then combined into scales (e.g. frequency and severity of respiratory symptoms, perceptions of treatment burden). Where appropriate, the items were formulated into questions based on the Cystic Fibrosis Questionnaire-Revised (CFQ-R), which has been well-validated [12, 25]. Some example CFQ-R items that were adapted to the PCD HRQoL measure include: "Did you cough during the day?" and "How often does CF get in the way of meeting your school, work, or personal goals?" Items were written to ensure conceptual, cultural and linguistic equivalence for North America, the UK and Ireland, by researchers from the USA, England and Ireland. We also adhered to both the FDA and EMEA Guidance $[13,22,23]$. For example, as recommended, we asked patients to answer questions based on their symptoms and impact over the past week.

\section{Cognitive interviews}

Cognitive interviews were conducted prior to formal psychometric validation of questionnaires to evaluate how respondents process the question and rating options cognitively; i.e. What "meaning" do these items have for respondents? Is this the same meaning we intended? What were they considering when rating frequency or impact? Specifically, we wanted to identify any problems with the instructions, organisation of the questionnaire, item interpretation, memory retrieval, decision-making processes and response selection. A "think aloud" procedure was used to investigate the participants' comprehension of the instructions, items and rating scales. They were asked clarifying questions, such as: "What were you thinking of when answering that question?" and "What does X word mean to you?" For example, "What does feeling 'well' mean to you?", "What would have made you endorse a higher/lower frequency for that question?", "How relevant/important is this question for you?", "Are the rating options clear to you?" and "Are they easy to use?"

Participants were first asked to complete the prototype questionnaire independently. Next, they were interviewed using specific cognitive probes, which focused on the clarity of the question, its meaning, relevance and importance, and what would have shifted their response to an adjacent answer. The audio of all interviews was recorded and transcribed. The results were discussed during a series of teleconferences to determine whether revisions were required for the format, instructions or items. The measure was refined based on the cognitive interviews and then finalised.

\section{Results}

Item generation

Items were generated by the expert panel and the qualitative, open-ended interviews with patients. Characteristics of participants who completed the open-ended interviews $(n=21)$ are shown in table 1. The majority of participants were female, and among US participants, most were between 18 and 35 years of age. As expected, nearly all adults described a chronic cough and sino-nasal symptoms. Eight (38\%) participants described themselves as infertile or had required assisted fertilisation, but 10 (48\%) participants had not yet tried to conceive or had their fertility status checked. Selected patient quotes from the open-ended interviews conducted with UK and North American participants are presented in table 2.

\section{Content analysis and item reduction}

Content analysis of the transcripts yielded the most important items for each of the 10 domains based on the frequency with which they were mentioned across adults. Saturation of content, across domains, was confirmed when no new themes emerged (figure 1). Our results indicated that this was achieved by the 5-7th interview, depending on the specific content area. We also harmonised the content across UK and North America to identify the most important topics. The items that were considered most important and relevant by the participants who performed the open-ended interviews were also scored as highly relevant by the 49 adult members of the PCD UK support group who completed the survey. Thus, content analysis of the interviews concurred with results of the survey (supplement table S). 


\section{TABLE 1 Demographics and clinical characteristics of participants}

\begin{tabular}{|c|c|c|c|}
\hline & Study population & UK & USA \\
\hline Participants n & 21 & 11 & 10 \\
\hline \multicolumn{4}{|l|}{ Sex } \\
\hline Male & $3(14)$ & $1(9)$ & $2(20)$ \\
\hline Female & $18(86)$ & $10(91)$ & $8(80)$ \\
\hline \multicolumn{4}{|l|}{ Age years } \\
\hline $18-35$ & $12(57)$ & $5(45)$ & $7(70)$ \\
\hline $36-50$ & $4(19)$ & $1(9)$ & $3(30)$ \\
\hline $51-65$ & $3(14)$ & $3(27)$ & \\
\hline$>65$ & $2(10)$ & $2(18)$ & \\
\hline \multicolumn{4}{|l|}{ Age at diagnosis years } \\
\hline$<5$ & $4(19)$ & $1(9)$ & $3(30)$ \\
\hline $5-12$ & $4(19)$ & 0 & $4(40)$ \\
\hline $12-18$ & $1(5)$ & $1(9)$ & 0 \\
\hline$>18$ & $12(57)$ & $9(82)$ & $3(30)$ \\
\hline \multicolumn{4}{|l|}{ Race/ethnicity } \\
\hline \multicolumn{4}{|l|}{ UK } \\
\hline White British & & 9 (82) & \\
\hline British Asian & & $1(9)$ & \\
\hline Asian & & $1(9)$ & \\
\hline \multicolumn{4}{|l|}{ USA } \\
\hline Caucasian & & & $10(100)$ \\
\hline Hispanic & & & $9(90)$ \\
\hline White non-Hispanic & & & $1(10)$ \\
\hline \multicolumn{4}{|l|}{ Symptoms } \\
\hline Chronic wet cough & $21(100)$ & $11(100)$ & 10 (100) \\
\hline Persistent runny nose & $20(95)$ & $11(100)$ & $9(90)$ \\
\hline Recurrent sinus disease & $16(76)$ & $8(72)$ & $8(80)$ \\
\hline Infertility & $8(38)$ & $4(36)$ & $4(40)$ \\
\hline Situs abnormalities & $12(57)$ & $8(72)$ & $4(40)$ \\
\hline Cardiac disease & 0 & 0 & 0 \\
\hline \multicolumn{4}{|l|}{$\mathrm{FEV}_{1} \# \%$ predicted } \\
\hline Range & & $31-98$ & $29-102$ \\
\hline Mean \pm SD & & $64 \pm 21$ & $65 \pm 25$ \\
\hline \multicolumn{4}{|l|}{ Employment status } \\
\hline In paid employment & $11(52)$ & $4(36)$ & $7(70)$ \\
\hline Student & $4(19)$ & $2(18)$ & $2(20)$ \\
\hline Retired due to age & $1(5)$ & $1(9)$ & 0 \\
\hline Retired/left work due to PCD & $4(19)$ & $3(27)$ & $1(10)$ \\
\hline Carer for dependants & $1(5)$ & $1(9)$ & 0 \\
\hline Other & 0 & 0 & 0 \\
\hline \multicolumn{4}{|l|}{ Marital status } \\
\hline Single & $5(24)$ & $3(27)$ & $2(20)$ \\
\hline Living with partner/spouse & $16(76)$ & $8(73)$ & $8(80)$ \\
\hline Separated from partner/spouse & & 0 & 0 \\
\hline Widowed & & 0 & 0 \\
\hline \multicolumn{4}{|l|}{ Fertility } \\
\hline Conceived naturally & & $3(27)$ & 0 \\
\hline Conceived through IVF & & $1(9)$ & $2(20)$ \\
\hline Infertility & & $3(27)$ & $2(20)$ \\
\hline Not yet known & & $4(36)$ & $6(60)$ \\
\hline
\end{tabular}

Data are presented as $\mathrm{n}(\%)$, unless otherwise stated. ${ }^{\#}$ : forced expiratory volume in $1 \mathrm{~s}(\mathrm{FEV} 1)$ is based on $\mathrm{n}=5$ participants in the UK and $\mathrm{n}=8$ in North America; data were unavailable for telephone interviews.

\section{Cognitive testing}

Cognitive interviews were conducted with 15 adults (UK $n=9$, USA $n=6$ ). Review of these transcripts indicated that patients found the items clear, important and relevant and had no difficulty with the response options. Six items were added, based on patient input, after the cognitive testing phase (table 3 ). These topics included: making plans for the future (vacation, attending family events), treatment burden, intimacy, and pain associated with sinus disease. Thus, the final prototype instrument contained 48 items 
TABLE 2 Participant quotes by topic

Topic

Quote

Country of

interviewee/sex/age

band in years

\begin{tabular}{|c|c|c|}
\hline \multirow{3}{*}{$\begin{array}{l}\text { Impact of respiratory } \\
\text { symptoms }\end{array}$} & "I had to tell the group not to worry because & UK/female/36-50 \\
\hline & I start huffing and spluttering as I'm walking." & \\
\hline & $\begin{array}{c}\text { "When I listen to myself breathe, I always } \\
\text { wheeze." }\end{array}$ & USA/female/18-35 \\
\hline \multirow[t]{2}{*}{ Impact of sinus symptoms } & $\begin{array}{c}\text { "I'm always blowing my nose, doesn't matter } \\
\text { what weather it is." }\end{array}$ & UK/female/36-50 \\
\hline & $\begin{array}{c}\text { "I always have to blow my nose before I eat if I } \\
\text { wanna taste anything." }\end{array}$ & USA/female/36-50 \\
\hline \multirow[t]{2}{*}{$\begin{array}{l}\text { Impact of ear } \\
\text { symptoms/ } \\
\text { hearing loss }\end{array}$} & $\begin{array}{c}\text { "You have to ask people to repeat themselves } \\
\text { so many times, they're just, like, 'oh don't } \\
\text { worry about it'." }\end{array}$ & UK/male/18-35 \\
\hline & $\begin{array}{l}\text { "I can't go white water rafting because I have } \\
\text { tubes in my ears and my ears can't get wet." }\end{array}$ & USA/female/18-35 \\
\hline \multirow[t]{2}{*}{ Impact of fertility issues } & $\begin{array}{l}\text { "Finding out that I possibly can't have kids; } \\
\text { that's when it started to panic me a little bit." }\end{array}$ & UK/male/18-35 \\
\hline & $\begin{array}{l}\text { "I'm still very uncertain if I ever wanna have } \\
\text { children because I don't know how me having } \\
\text { this illness will affect them." }\end{array}$ & USA/female/18-35 \\
\hline \multirow[t]{2}{*}{$\begin{array}{l}\text { Impact of treatment } \\
\text { burden }\end{array}$} & $\begin{array}{l}\text { "I don't really want to do it; it's kind of boring } \\
\text { and it's not fun and I'd rather do something } \\
\text { else. But obviously you have to do it." }\end{array}$ & UK/female/18-35 \\
\hline & $\begin{array}{l}\text { "I think it just requires more planning. } \\
\text { I need to wake up earlier or start getting ready } \\
\text { for bed earlier, I need to come home from } \\
\text { work and do this; it's just more planning." }\end{array}$ & USA/female/18-35 \\
\hline \multirow[t]{2}{*}{ Emotional functioning } & $\begin{array}{c}\text { "I'm so frustrated with this illness, I just want } \\
\text { it to go away, but, unfortunately, that's how } \\
\text { I have to live." }\end{array}$ & UK/male/18-35 \\
\hline & $\begin{array}{l}\text { "...if you go to the doctor [and] you're feeling } \\
\text { pretty good and you know your numbers are } \\
\text { not good; that can be a big cause of anxiety." }\end{array}$ & USA/female/18-35 \\
\hline \multirow[t]{2}{*}{ Social functioning } & $\begin{array}{c}\text { "It has had such a huge impact on my life, and } \\
\text { certainly I think it's contributed to the breakup } \\
\text { of my first marriage." }\end{array}$ & UK/female/50-64 \\
\hline & $\begin{array}{l}\text { “...there have been times where l've had to } \\
\text { cancel things because l've gotten sick. Getting } \\
\text { sick can happen overnight; you're fine one day } \\
\text { and the next day you feel awful." }\end{array}$ & USA/female/18-35 \\
\hline
\end{tabular}

(QOL-PCD v1.2). Following this iterative process, the draft version of the QOL-PCD v.1.2 is ready to be tested in a psychometric validation study.

\section{Discussion}

This process, conducted in the UK and North America, yielded the first HRQoL instrument for adults with PCD, the QOL-PCD. It was developed following the guidelines published by the major regulatory bodies in Europe and the USA (i.e. EMEA and FDA) $[13,22,23]$ and will be submitted to these agencies for consideration as an outcome measure for clinical trials. The most important principle governing its development was our reliance on patient input and their perspective at each phase. Thus, this tool systematically reflects how an adult with PCD "survives, feels, or functions" [13]. Given the rarity of this chronic disease, we developed the content cross-culturally in English-speaking countries (UK, USA and Canada) and found no discrepancies in content across countries. Additional input was obtained from the current literature and from medical experts across Europe and North America.

Open-ended interviews highlighted the importance not only of patients' respiratory symptoms, but the effects of sinus disease and hearing problems on daily functioning. Although sinus disease is also 
Respiratory symptoms

UK participants

\begin{tabular}{lcccccccccccc} 
& 1 & 2 & 3 & 4 & 5 & 6 & 7 & 8 & 9 & 10 & 11 & Total \\
\hline Cough & 1 & 1 & 1 & 1 & 1 & 1 & 1 & 1 & 1 & 1 & 1 & 11 \\
Shortness of breath & 1 & 1 & 1 & 1 & 1 & 1 & 1 & 0 & 1 & 1 & 0 & 9 \\
Chest congestion & 1 & 1 & 1 & 1 & 1 & 1 & 1 & 0 & 0 & 1 & 1 & 9 \\
Cough up mucus & 1 & 0 & 1 & 1 & 1 & 1 & 1 & 0 & 0 & 1 & 1 & 8 \\
Chest tightness & 1 & 1 & 0 & 0 & 1 & 0 & 1 & 0 & 0 & 0 & 1 & 5 \\
$\begin{array}{l}\text { Wheezing } \\
\text { Cough interrupts sleep }\end{array}$ & 0 & 1 & 1 & 0 & 1 & 0 & 0 & 0 & 0 & 0 & 1 & 4 \\
Chest pain & 0 & 1 & 1 & 0 & 0 & 0 & 0 & 0 & 0 & 0 & 1 & 3 \\
\hline $\begin{array}{l}\text { Cough with exertion } \\
\text { Chest pain with exertion }\end{array}$ & 0 & 0 & 0 & 0 & 1 & 1 & 0 & 0 & 0 & 0 & 1 & 3 \\
$\begin{array}{l}\text { Sleep disturbances from } \\
\text { chest pain }\end{array}$ & 0 & 0 & 1 & 1 & 0 & 0 & 1 & 0 & 0 & 0 & 0 & 3 \\
\hline
\end{tabular}

Rhino-sinus symptoms

\begin{tabular}{lllll|llllllll}
\hline Runny nose & 1 & 1 & 1 & 1 & 1 & 1 & 1 & 1 & 1 & 1 & 1 & 11 \\
Stuffy nose & 1 & 0 & 1 & 1 & 0 & 0 & 0 & 1 & 0 & 1 & 0 & 5 \\
Post-nasal drip & 1 & 0 & 0 & 0 & 0 & 0 & 0 & 1 & 0 & 0 & 0 & 2 \\
Sinus pain/headache & 0 & 0 & 1 & 1 & 0 & 0 & 0 & 0 & 0 & 0 & 0 & 2 \\
\hline Sinus surgery & 1 & 0 & 0 & 1 & 0 & 0 & 0 & 0 & 0 & 0 & 0 & 2 \\
Difficulty smelling & 1 & 0 & 0 & 1 & 0 & 0 & 0 & 0 & 0 & 0 & 0 & $22^{\#}$ \\
Sinus congestion & 1 & 0 & 1 & 0 & 0 & 0 & 0 & 0 & 0 & 0 & 0 & 2 \\
Sinus pressure & 0 & 0 & 1 & 0 & 0 & 0 & 0 & 0 & 0 & 0 & 0 & 1 \\
Difficulty tasting & 0 & 0 & 0 & 1 & 0 & 0 & 0 & 0 & 0 & 0 & 0 & 1 \\
\hline
\end{tabular}

Ear and hearing symptoms

\begin{tabular}{ll|lllllllllll}
\hline Trouble hearing & 1 & 0 & 1 & 0 & 1 & 0 & 0 & 0 & 1 & 1 & 1 & 6 \\
Ears blocked & 1 & 0 & 1 & 0 & 1 & 0 & 0 & 0 & 1 & 0 & 1 & 5 \\
\hline Ear ringing & 0 & 0 & 0 & 0 & 0 & 0 & 0 & 0 & 0 & 0 & 0 & 0 \\
Problems with balance & 0 & 0 & 0 & 0 & 0 & 0 & 0 & 0 & 0 & 0 & 0 & 0 \\
\hline
\end{tabular}

US participants

\begin{tabular}{|c|c|c|c|c|c|c|c|c|c|c|c|}
\hline & 1 & 2 & 3 & 4 & 5 & 6 & 7 & 8 & 9 & 10 & Total \\
\hline Cough & 1 & 1 & 1 & 0 & 1 & 1 & 1 & 1 & 1 & 1 & 9 \\
\hline Chest congestion & 0 & 1 & 0 & 1 & 1 & 1 & 1 & 1 & 1 & 0 & 7 \\
\hline Chest pain & 1 & 1 & 0 & 1 & 1 & 0 & 1 & 1 & 0 & 1 & 7 \\
\hline Cough up mucus & 1 & 0 & 1 & 1 & 0 & 1 & 1 & 0 & 0 & 0 & 5 \\
\hline Shortness of breath & 0 & 0 & 1 & 0 & 1 & 0 & 0 & 1 & 1 & 1 & 5 \\
\hline Chest tightness & 1 & 0 & 1 & 1 & 0 & 0 & 0 & 0 & 0 & 1 & 4 \\
\hline Cough interrupts sleep & 1 & 0 & 1 & 0 & 1 & 0 & 0 & 0 & 0 & 0 & 3 \\
\hline Wheezing & 1 & 0 & 1 & 0 & 0 & 0 & 0 & 0 & 1 & 0 & 3 \\
\hline Cough with exertion & 0 & 1 & 0 & 0 & 0 & 0 & 0 & 0 & 0 & 0 & 1 \\
\hline $\begin{array}{l}\text { Sleep disturbances from } \\
\text { chest pain }\end{array}$ & 0 & 1 & 0 & 0 & 0 & 0 & 0 & 0 & 0 & 0 & 1 \\
\hline Chest pain with exertion & 1 & 0 & 0 & 0 & 0 & 0 & 0 & 0 & 0 & 0 & 1 \\
\hline
\end{tabular}

\begin{tabular}{lllll|lllllll}
\hline Stuffy nose & 1 & 1 & 0 & 1 & 1 & 1 & 1 & 1 & 1 & 0 & 8 \\
Sinus pain/headache & 1 & 1 & 0 & 1 & 1 & 1 & 0 & 1 & 1 & 1 & 8 \\
Runny nose & 1 & 1 & 0 & 0 & 1 & 0 & 1 & 1 & 1 & 1 & 7 \\
Post-nasal drip & 0 & 0 & 0 & 1 & 0 & 1 & 0 & 0 & 1 & 1 & 4 \\
\hline Difficulty smelling & 0 & 1 & 0 & 0 & 1 & 0 & 0 & 1 & 1 & 1 & $5^{\#}$ \\
Sinus surgery & 1 & 1 & 0 & 0 & 0 & 0 & 0 & 1 & 0 & 1 & 4 \\
Difficulty tasting & 0 & 1 & 0 & 1 & 1 & 0 & 0 & 0 & 0 & 0 & 3 \\
Sinus congestion & 0 & 0 & 0 & 1 & 1 & 0 & 0 & 0 & 1 & 0 & 3 \\
Sinus pressure & 1 & 0 & 0 & 0 & 0 & 0 & 0 & 0 & 0 & 0 & 1 \\
\hline
\end{tabular}

\begin{tabular}{lcccccc|ccccc}
\hline Trouble hearing & 1 & 1 & 1 & 1 & 1 & 1 & 1 & 1 & 1 & 1 & 10 \\
Ears blocked & 0 & 1 & 0 & 1 & 0 & 0 & 0 & 1 & 1 & 1 & 5 \\
\hline Ear ringing & 0 & 0 & 0 & 0 & 0 & 1 & 0 & 1 & 0 & 0 & 2 \\
Problems with balance & 1 & 0 & 0 & 0 & 0 & 0 & 0 & 0 & 0 & 0 & 1 \\
\hline
\end{tabular}

FIGURE 1 Saturation grids for UK and US participants: respiratory symptoms, sinus symptoms, and ear and hearing symptoms. Vertical lines indicate saturation was reached. All items above the horizontal lines were retained for the final questionnaire. Shaded cells refer to the first time the item was mentioned. " : participants did not indicate adverse effects of difficulty smelling; therefore it was not included in the final questionnaire.

problematic for patients with CF and non-CF bronchiectasis, patients with PCD emphasised the additional impact of their upper respiratory tract symptoms. This highlights that PCD has distinct features from other bronchiectatic diseases [26], and deserves individualised management. Thus, a number of items assessing rhino-sinus and ear symptoms appear on the final instrument, differentiating it from disease-specific HRQoL measures for adults with CF or non-CF bronchiectasis [12, 27].

The study population was not fully representative of the PCD population. In common with many previous studies, it was more difficult to recruit men than women with only three men (14\%) participating in the interviews. Approximately $6 \%$ of patients with PCD have cardiovascular disease [5]. None of the 21 interviewees in this study had cardiovascular disease, but even if we had designed the study population to be representative of the PCD population we would have aimed to have only one patient. Moreover, we would not be able to recruit patients with the diverse spectrum of cardiac disease e.g. complex cyanotic heart disease versus simple cardiac anomaly. It is therefore a limitation of the questionnaire that it does not include items relevant to patients with cardiac disease.

A reliable patient-reported outcome measure for PCD is particularly important, given that physiological measures such as forced expiratory volume in $1 \mathrm{~s}$ and LCI are not sensitive or predictive, and HRCT is not suitable for repeat testing due to radiation exposure. Importantly, the QOL-PCD provides a measure of the multidimensional effects of PCD on adults, from their own perspective including its impact on the upper and lower respiratory systems, treatment burden and social and emotional functioning. Reliability and validity studies are currently in process and will be reported in due course.

In summary, the QOL-PCD was developed and has undergone cognitive testing in adults from several English-speaking countries. It has been translated into Dutch, German, and Danish, with plans to develop translations from major European countries and the Middle East. A multi-national, psychometric field-study is now planned to assess several forms of reliability and validity. Similar processes have been used to develop age-specific HRQoL measures for children and adolescents with PCD and parent caregivers. These instruments will also be translated into other languages and validated in future studies. 


\section{TABLE 3 Summary of modifications to QOL-PCD after cognitive testing}

\section{Modifications after cognitive testing}



\section{Acknowledgements}

Research in Southampton is supported by NIHR Southampton Respiratory Biomedical Research Unit, NIHR Wellcome Trust Clinical Research Facility and AAIR Charity. Members of the PCD European Group provided expert opinion; JSL, MWL and LB are members of ERS Task Force for PCD Diagnostics (ERS TF-2014-04). JSL leads EU-funded COST Action BEAT-PCD (BM1407). Members of the PCD Support Group, UK (Chair Fiona Copeland) and PCD Foundation, North America (Director Michele Manion) contributed to all aspects of study conduct.

\section{References}

1 Lucas JS, Burgess A, Mitchison HM, et al. Diagnosis and management of primary ciliary dyskinesia. Arch Dis Child 2014; 99: 850-856.

2 Lucas JS, Walker WT, Kuehni CE, et al. Primary ciliary dyskinesia. In: Cordier J-F, ed. Orphan Lung Diseases (ERS Monograph). Sheffield, European Respiratory Society, 2011; pp. 201-217.

3 Knowles MR, Daniels LA, Davis SD, et al. Primary ciliary dyskinesia. Recent advances in diagnostics, genetics, and characterization of clinical disease. Am J Respir Crit Care Med 2013; 188: 913-922.

4 Noone PG, Leigh MW, Sannuti A, et al. Primary ciliary dyskinesia: diagnostic and phenotypic features. Am J Respir Crit Care Med 2004; 169: 459-467.

5 Shapiro AJ, Davis SD, Ferkol T, et al. Laterality defects other than situs inversus totalis in primary ciliary dyskinesia: insights into situs ambiguus and heterotaxy. Chest 2014; 146: 1176-1186.

6 Maglione M, Bush A, Montella S, et al. Progression of lung disease in primary ciliary dyskinesia: is spirometry less accurate than CT? Pediatr Pulmonol 2012; 47: 498-504.

7 Irving SJ, Ives A, Davies G, et al. Lung clearance index and high-resolution computed tomography scores in primary ciliary dyskinesia. Am J Respir Crit Care Med 2013; 188: 545-549. 
8 Green K, Buchvald FF, Marthin JK, et al. Ventilation inhomogeneity in children with primary ciliary dyskinesia. Thorax 2012; 67: 49-53.

9 Guyatt GH, Feeny DH, Patrick DL. Measuring health-related quality of life. Ann Intern Med 1993; 118: 622-629.

10 Quittner AL, Modi A, Cruz I. Systematic review of health-related quality of life measures for children with respiratory conditions. Paediatr Respir Rev 2008; 9: 220-232.

11 Turner RR, Quittner AL, Parasuraman BM, et al. Patient-reported outcomes: instrument development and selection issues. Value Health 2007; 10: Suppl. 2, S86-93.

12 Quittner AL, Buu A, Messer MA, et al. Development and validation of The Cystic Fibrosis Questionnaire in the United States: a health-related quality-of-life measure for cystic fibrosis. Chest 2005; 128: 2347-2354.

13 U.S. Department of Health and Human Services; Food and Drug Administration. Guidance for industry. Patient-reported outcome measures: use in medical product development to support labeling claims. Dec 2009. www.fda.gov/downloads/Drugs/GuidanceComplianceRegulatoryInformation/Guidances/UCM193282.pdf Date last accessed: March 30, 2015.

14 Wilson IB, Cleary PD. Linking clinical variables with health-related quality of life. A conceptual model of patient outcomes. JAMA 1995; 273: 59-65.

15 Ferrans CE, Zerwic JJ, Wilbur JE, et al. Conceptual model of health-related quality of life. J Nurs Scholarsh 2005; 37: $336-342$.

16 McManus IC, Mitchison HM, Chung EM, et al. Primary ciliary dyskinesia (Siewert's/Kartagener's syndrome): respiratory symptoms and psycho-social impact. BMC Pulm Med 2003; 3: 4.

17 McManus IC, Stubbings GF, Martin N. Stigmatization, physical illness and mental health in primary ciliary dyskinesia. J Health Psychol 2006; 11: 467-482.

18 Pifferi M, Bush A, Di CM, et al. Health-related quality of life and unmet needs in patients with primary ciliary dyskinesia. Eur Respir J 2010; 35: 787-794.

19 Carotenuto M, Esposito M, Di PF, et al. Psychological, cognitive and maternal stress assessment in children with primary ciliary dyskinesia. World J Pediatr 2013; 9: 312-317.

20 Whalley S, McManus IC. Living with primary ciliary dyskinesia: a prospective qualitative study of knowledge sharing, symptom concealment, embarrassment, mistrust, and stigma. BMC Pulm Med 2006; 6: 25.

21 Schofield LM, Horobin HE. Growing up with primary ciliary dyskinesia in Bradford, UK: exploring patients experiences as a physiotherapist. Physiother Theory Pract 2014; 30: 157-164.

22 Apolone G, De Carli G, Brunetti M, et al. Health-related quality of life (HR-QOL) and regulatory issues. An assessment of the European Agency for the Evaluation of Medicinal Products (EMEA) recommendations on the use of HR-QOL measures in drug approval. Pharmacol Econ 2001; 19: 187-195.

23 European Agency for the Evaluation of Medicinal Products (EMEA): Committee for Medicinal Products for Human Use (CMHP). Reflection paper on the regulatory guidance for the use of health-related quality of life (HRQL) measures in the evaluation of medicinal products. 2005. Available from www.ispor.org/workpaper/emeahrql-guidance.pdf Date last accessed: March 30, 2015.

24 Lucas JS, Chetcuti P, Copeland F, et al. Overcoming challenges in the management of primary ciliary dyskinesia: the UK model. Paediatr Respir Rev 2014; 15: 142-145.

25 Quittner AL, Sawicki GS, McMullen A, et al. Psychometric evaluation of the Cystic Fibrosis Questionnaire-Revised in a national sample. Qual Life Res 2012; 21: 1267-1278.

26 Lucas JS, Carroll M. Primary ciliary dyskinesia and cystic fibrosis: different diseases require different treatment. Chest 2014; 145: 674-676.

27 Quittner AL, Marciel KK, Salathe MA, et al. A preliminary quality of life questionnaire-bronchiectasis: a patient-reported outcome measure for bronchiectasis. Chest 2014; 146: 437-448. 